\title{
TECHNICAL DIMENSIONS OF 30 PRINTING TECHNIQUES IN THE FIELD OF ARTS AND THE EDUCATION SYSTEM
}

\author{
By \\ Prof.Ass. Muwaffaq Abdulmajid. \\ Public Authority for Applied Education \& \\ Training Art Education dept. \\ State of Kuwait
}

Research Gournal Specific Fducation

Faculty of Specific Education

glansoura University

ISSUE NO. 59, JULY, 2020

مجلة بعوث التربية النوعية - جامعة المنصورة

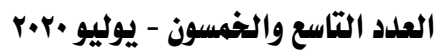




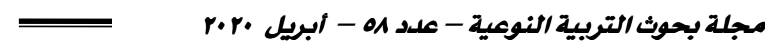

\title{
TECHNICAL DIMENSIONS OF 30 PRINTING TECHNIQUES IN THE FIELD OF ARTS AND THE EDUCATION SYSTEM
}

\author{
Prof.Ass. Muwaffaq Abdulmajid. *
}

\section{Abstract}

3D printing technologies are controlling the functioning of many machines, process, or different system in technical skills. Consequently, the present research investigates these performances as has come into view among the considerable scholarly regulations. The present research demonstrated teaching the students the application of 3D printing techniques in universities. Furthermore, to demonstrate teaching educators as well as an assistive technology for the sake of educating the related materials of 3D printing techniques. The present research provides a review of the literature, considering where and how 3DP could utilise. The research showed that the educational system is requested to construct curricula and an experimental methodology as an aid for Educational process.

Keywords: 3D printing, art education, assistive technology, experimental methodology.

\section{INTRODUCTION}

\section{A. Definition Of The 3Dprinting:}

Ford et al. (2017) [1], Singh et al. (2017) [2] reported that 3Dprinting is an additive method of manufacturing. The 3Dprinting adds material in sequential patterns to innovate the desired form. By building up layer on layer, allows for much utmost flexibility and innovate in the design process. No longer have the designers to design for manufactured any articles, but instead, they can create a part that is lighter and stronger employing 3Dprinting design.

$3 \mathrm{D}$ printing is a technology that solving real-world problems where scientists and engineers are using to change the world. By putting that same technology available to students to face some of the challenges to the

\footnotetext{
* Public Authority for Applied Education \& Training Art Education dept. State of Kuwait
} 
community, the students will learn empathy, teamwork, and problem solving on a real-world problem. According to the $3 \mathrm{D}$ printing students in Australia at St Stephen's School could solve a medical problem to create the sample [3].

\section{CONCEPTUAL FRAMEWORK}

\section{A. The research problem}

It might be stated in the following question:

- What is the effectiveness of using 3Dprint as an approach to teaching the fundamentals design of artwork?

- What is the efficacy of using 3Dprint in developing the students' analytical thinking skills in the design field in art education?

\section{B. Objectives of the Study}

The main objectives of this research are:

- To teach students and educators concerning3DP;

- To supply technology during teaching;

- To produce artefacts that aid learning;

- To create assistive technologies; and support outreach activities.

\section{Research Methodology}

By employing the qualitative and analysing methodology, the researcher attempted to illuminate how comprising a 3Dprint design assignment into the artwork to give supporting and challenging the students' artwork content and technological literacies.

\section{Significance of the research}

- The research is a starting point for researchers who used 3Dprint as an approach to teaching the fundamentals of art design in higher education.

- The research may attract supervisors, educators and instructors in general, and computer learners in particular for varying education strategies.

- The study emphasises the importance of acquiring analytical thinking 
skills through visual learning and students' learning styles.

- Give specific emphasis on the necessity of modifying the educating approaches.

- Triggering the students' motivation by utilising a new method of learning.

- An opportunities for curricula projects and developers to the requirement of activating the visual approach as advanced curriculum.

\section{E. Research goal}

The integrated adoption of 3DP into the teaching syllabus has three main benefits:

- Promote student-centred learning and led to observable improvements in student work.

- Promote the relationship between students and lecturers as eLearning has taken place.

- Links students' learning to their ethical responsibilities in the world, such as environmental sustainability.

- Connect the balance of power of the student-centred learning with the learning experience shifting from the lecturer to the student.

\section{REVIEW OF LITERATURES}

The purpose of Radniecki (2016) [4] investigation is to show how the academic libraries provide resources to assist users with the necessary $3 \mathrm{D}$ modelling practicing to innovate successfully 3D print objects. The supplied tutorials are Online on numerous 3D printing modelling at different programs. The library is providing three axes for Design;

- Methodology and approach workshop by supplying 3D modelling instruction,

- Availability groups for individual consultations with 3D modelling expertise.

- Services workshop attendance. 
As more libraries begin providing access to maker technologies, Originality/value, the few attendances are addressing the request to teach new skills and literacies basically to apply those technologies in fully application.

Goulas et al. (2016)[5]reported in a research paper investigated the application of a powder bed fusion AM process as a possibility onsite fabrication approach for processing components out of Lunar Moon dust. It was shown that this technique category has the capability to directly manufacture multi-layered parts out of lunar regolith, which has potential applicability to future moon colonization.

Recently, 3D print [6] strike the art and fashion design world, its potential inspiring the adaptability of the fashion designer. Instead of traditionally sculpting, sculptures Artists are inspiring printing statues. Using 3D scans of some of the museum's sculptures.

$3 \mathrm{D}$ printing is allowing artists more possibilities and designs with unlimited landscape for their innovations. One of the newest innovators are The Laser Girls as shown in fig (1), by high-end industrial printers. The Laser Girls established to mix these new dimensions and enter the field as never showed before. Moreover, in the 3D art world wearable colourful manicure nails has been figured as shown in fig (2). The printed nails were in metals and plastics, showing an aesthetic and wearable piece that is a glamour and artistic style. Beside The work is functional but shows expertise in 3D printing technology and engineering [7].

Because the statue is made of layers in 3D printing, 3D prints often have $x, y, z$ layer lines as shown in fig (3) [8].

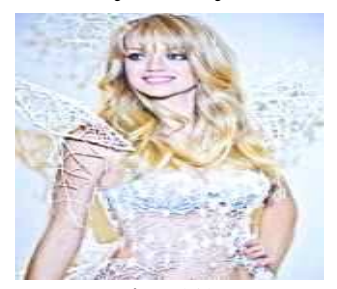

Fig (1).

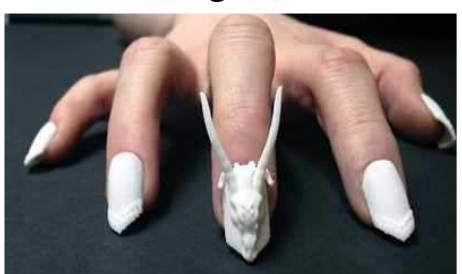

Fig (2).

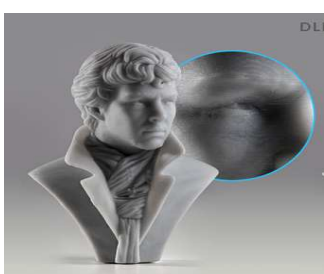

Fig (3). 
Reuscher (2014) [9] and other [10] reported that 3D Printing is not the answer to every type of production; however, its advancement is assisting in accelerating design and engineering more than ever before. Through the use of 3D printers, designers could create one of any kind piece of art, intricate building, and product designs and also make parts while in space. The point is the too early time at which 3DP starts to realise the impact of 3D Printing in the many industry fields. 3D Printing could conduct the revolutionary of the next industrial age.

Kalita et al. (2020) [11] are providing a synopsis of digital Technology consolidation in higher educational disciplines. The issues concerning: teacher inability to incorporate digital thinking into student learning, student non-adaptability to modern technologies, the unreliability of digital educational resources, and lack of infrastructure/power supply in most of the educational institutes. An active digital learning approach in students and extensive training sessions for digital utilisation excellence in teachers and educators are a few ways to solve issues regarding the integration.

\section{APPLICATIONS}

\section{A. Software to work on automotive designs}

\section{A.1.Alias}

It is a software developed by Autodesk. It is an excellent tool to work on industrial designs, and especially for automotive projects. 3Ds Max is the best solution, is an accurate tool, mostly used by professional designers to create high-end renderings. Alias is excellent software to make shape modelling, and it can be useful to make realistic car designs.

\section{A.2.Blender}

It is an open-source 3D software. It has simulation tools, and it supports polygon meshes and NURBS surfaces.

\section{A.3.SolidWorks}

It is considered as a powerful tool that assists transportation designers in developing innovative and effective models. This CAD 
software has an uncomplicated interface and uses for design, as well as to create mechanical parts.

\section{A.4.Creo Parametric}

It is a 3D modelling software that will help to create 3D models and to work on smart industrial designs. It is allowing working on the technical surfacing, 2D and 3D drawing as Designs and model assembly.

A.5.Auto $\boldsymbol{C A D}$ is modelling software developed by Autodesk.

It is a CAD software prevents mistakes during the manufacturing process to make 2D drawings and 3D models, CAD design program considered excellent for engineers.

\section{A.6.Inventor}

It has various modelling options and great simulation tools. This CAD software will surely help to improve performance.

\section{A.7.Catia}

It is 3D professional software generated by Dassault Systems'. Catia Is accommodate in the aeronautic and aerospace industry. It is ideal for mechanical engineering and could assist in creating mechanical parts, but also significant in automotive designs and on any product.

\section{A.8.SketchUp}

It is a practical tool to create any project from scratch and all the needed drawing.

\section{A.9.Rhino}

It is a professional instrument utilised by engineers and 3D designers. Rhino is beneficial in many different industries such as fashion design or architecture, also can apply in car design software. 


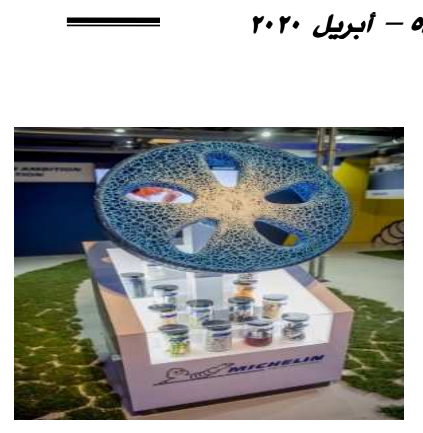

Fig (4)

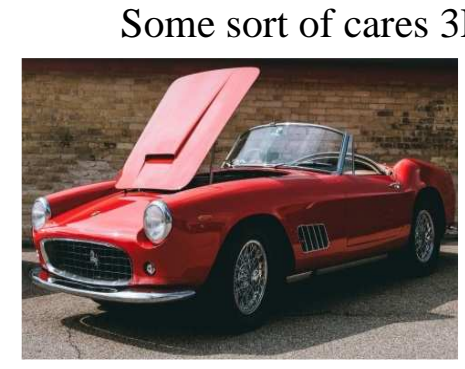

Fig (5)

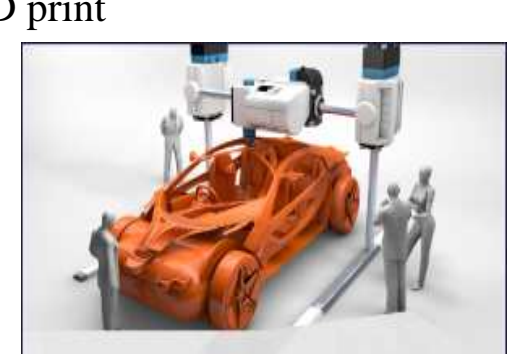

Fig (6)

Fig (4) 3D printed wheel by Michelin. $\quad$ Fig (5) 3D printing for classic car restoration.

Fig (6) 3D printer with car built up.

\section{3D PRINTING IN THE EDUCATION SYSTEM}

Irwin et al. (2014)[13] reported that during a Master's degree in Applied Science Education at Michigan Technological University, RepRap 3D printers were used as a course that introduced students to the design-build-test process. Post-course feedback from 18 completed surveys rated the course is highly effective learning. Furthermore, two high school biology teachers who were participants in the class also attended a two-day workshop to build a 3D printer. They were able to do so and to go on to use it to 3D print scientific apparatus for use in their classrooms.

Ford et al. (2017) [14] reported that 3D printing in the educational process follows the four principal pedagogical environments as follow: (1) school; (2) university; (3) library; and (4) particular education settings.

\section{THE CREATION OF 3D MODELS IS AN ESSENTIAL PRECURSOR TO 3DP.}

Go et al. (2016) [15] defined three accesses to the procurement of 3DP designs for university teaching, as follows:

- Students download the current designs from a database. With consideration of made aware of the technical capacities of 3DP, the used materials, the design restraints, and the variety of implied application areas for 3DP.

- As far as the "students were transformed from receptive consumers (database users) into dynamic and creative users hooking with the 
potentialities and boundaries of the $3 \mathrm{D}$ printing process, the procedure required an independent design. Consequently, students gained significant experience of 3D modelling for 3DP, in terms of the geometric design, stability and colour scheme.

- The approach involved 3D scanning, with students learning about the possibilities and limitations of 3D scanning, along with how to prepare this captured data for 3D printing. Testing out each of these three approaches meant that "students are then able to learn how technical hardware specifications impact on part design and how these limits might be overcome" Junk et al. (2015) [16].

\section{3D PRINTING IN UNIVERSITIES EDUCATION}

The decision making of chosen 3DP curricula is crucial in universities. Through the innovation of 3DP technology, literature could be applied to the acquisition of subject knowledge to cover each of scientific and test models as follows:

- The utilising of 3DP through project-based educating;

- The consolidation in existing courses of the progression 3DP skills into the curriculum through its incorporation.

- Eventually, new kinds of literature are developed; bearing in mind, an external engagement supported technical artwork in the university.

A significant use of 3DP at universities is in the sciences of artwork, where 3D models are created to support student learning in the lab or classroom. This application of 3DP to produce models as visual learning aids. In a similar vein, 3DP can be used to create test models for experiments. Elsewhere, MSc graduate students in the Faculty of art at the University of Belgrade used 3D printed components during fan and turbo compressor experiments, and fourth year aerospace engineering.

McGahern et al. (2015) [17] reported that as educators, F.B. and D.P. are now rethinking how to use and assign 3D printing for enhancing student learning outcomes. Printing the proteins by the 3D technology is to assist students in perceiving the molecular processes. By asking the student 
to construct a rest of a structure, they have designed as a way to enhance real learning. This method is to memorise the terms and locations is difficult to be remembered. However, as 3DP technology established at the institution, turned to improve requested assignments by students to innovate visual projects for different qualitative and quantitative courses. They tried to solve the problem of the printing and materials costs to relief the burdened of the expense.

Janković et al. (2016)[18] reported that the Personalized Learning in Anatomy science, for each student, 3D printed model applied in an active educating task. As three-dimensionally scanned a human skull used to fabricate a 3D printed model. By tracing counters lines and colouring individual skull orbital bones, and preserving the model for future study, Students engage in an innovated model during a practical class. 3DP technology can make possible the creation of appropriate learning resources that are vigorous, low-cost and willingly accessible to students.

\section{TEACHING UNIVERSITY STUDENTS ABOUT 3D PRINTING}

\section{A. How Is 3D Printing Being Used In Different Education Fields?}

Fernandes et al. (2016)[19] reported that to demonstrate theoretical concepts Learning styles with students, during the two year study of 3DP approval in the second year of an industrial design degree, was found that using 3D printed artefacts "could be classified at different groups of students. According to students preferred learning styles classified as active, reflexive, theoretical and pragmatic. The higher the applied methodological variety in higher education, the more efficient is receiving for most students

Traditionally, the lecturer would have the significant practical expertise to transfer the skills to the students. However, this is often not the situation with advanced technology such as 3DP. Besides, the unconventionality of the technology means that internet resources are more accurate and up-to-date than the limited number of 3DP publications.

Loy (2014)[20] declared that as far as the rapidity of 3DP developments, the student is as likely more as a cohort to be bringing new information on the spread of the technology to the classroom by the lecturer. 
That means that the lecturer will be learning alongside the class, acting less as a leader and more a classroom mentor. Experiences at Griffith University indicated that a 'flipped classroom' approach as part of a blended learning strategy was positive for both lecturers and students.

Liou et al. (2012) [21] reported that there are various possibilities for students to obtain 3DP skills at the Missouri University of Science and Technology. With 3DP experiences development possibilities however, available various courses centring on design and basic CAD system modelling; product modelling; fast prototyping; consolidate product development; as well as advanced level courses.

In recent years scientists and Biomedical Engineering have already able to utilise 3D printing technology for industrialised body and parts of organs. Through 3D Printing, The first complete organ built is predictable to be done very soon. The proceeding of innovating the organ of the body part is the same as well as innovating plastic or metal part. However, alternatively, the specific raw material, of course, is biological cells fabricated in a lab. As far as the fabrication of the human cell is specifically for a particular patient, therefore, the patient can be confident that his body will not reject the organ.

Jaksic (2014) [22] explained that at Colorado State University Pueblo, 3DP is being used in industrial engineering and mechatronics programmes with an integrated courses. The investigation represented methodically the influence of 3D-printing technology, in the urological field. The Patient is counselling and gaining surgical training and planning appears to have the advantage of these advanced technological opportunities. 3D-printed Anatomical prototypes for surgical planning have a comprehensive arrangement of applications in the hospital with a patient under treatment while staying in a hospital as shown in fig (7). 


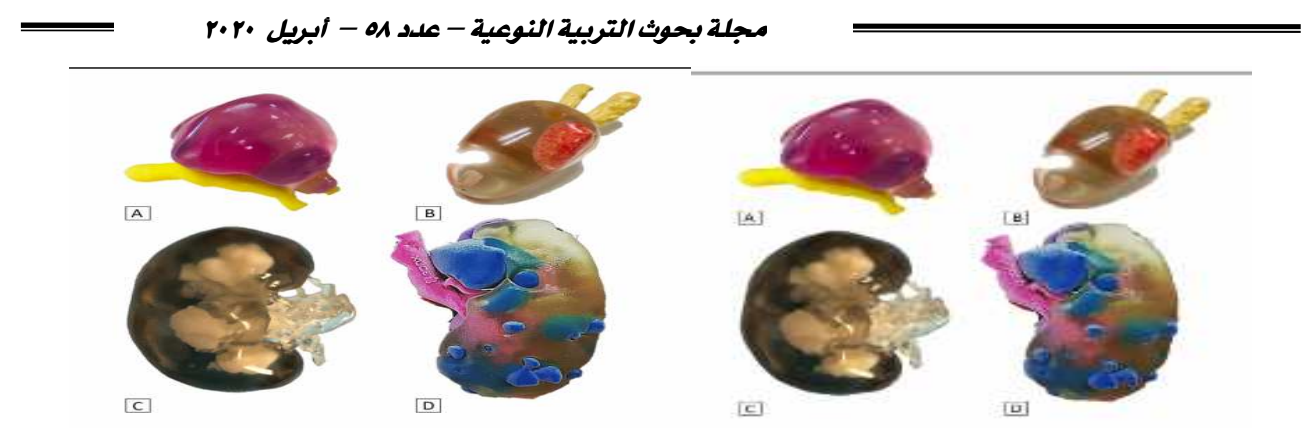

Fig (7)

Examples of using 3D printing in urology

(A)Prostate with lesion and neurovascular bundles. (B) Prostate with visible wound used for patient teaching. (C) Kidney with stag horn stone used for the surgical process. (D) Kidney with multiple lesions and its vascular ramifications in patients used for both patient education and surgeon process.

The goal of the Lab and workshop is to supply the context for the actual curricula and to distinguish and develop effective pedagogical practices for superior manufacturing technologies in the educational process. The presentation of principles, elements and tools of exceptional manufacturing in the higher education could assist in introducing all students to the fields of 3DP construction and different area of the educational process. This technology could inspire students to pursue careers in this field who otherwise might not have this possibility.

AlAli (2018)[23] carried out an investigation dealt with the use of the 3D-printed technique in educational seminars on cleft lip and palate and conducted that by confronting integrated workshops of "hands-on" student, with $2 \mathrm{D}$ presentation seminar methods by using a pre-seminar and postseminar assessments level of acquired knowledge was determined. A significant improvement in was gained by the utilising of the 3D-printed model resulted as a high mean percentage of experience learned the visualisation tools in medical education, proved that the employment of 3Dprinted technique and the potential of 3D-printing technology became a standard and efficient tool in the interpretation of 2D imaging. 
Losco et al., (2017) [24] and others Wilson et al. (2018) [25], Vaccarezza, 2018) [26] investigating relevant studies considering the impact of different educational curricula in anatomical education. The investigation throws shade lights on the potential function of new instructional methods such as the employing of 3D-printed technique in educating process and teaching anatomy. In essence, specimens of 3D-printed could be a valuable supplementary tool, especially in contexts where epidermal dissection is restrained by lack of facilities. Furthermore, when dealing with human organs, avoid confronting a problematic and religious cultural background.

Teaching students 3DP technology and improve their skills is an essential characteristic between this literature and other technologies involves the active and passive assimilation of 3DP into curricula. Dynamic adaptation consists of the improvement of courses and projects which have a specific focus on the teaching of 3DP skills. In opposition, passive integration requires the use of 3DP during sessions and projects to promote the learning of other subjects.

\section{3D PRINTING TEACHING EDUCATORS}

Bull et al.(2014)[27]As a new digital fabrication technology, 3DP is not immune to these integration challenges; Bull et al. remark that in the school system "the current generation of teachers is not well positioned to take advantage of these capabilities.

Maloy et al. (2017) [28] indicated that a more general need in the education system of teaching educators about 3DP, supporting their professional development, and enabling their ability to teach others about 3DP. Reflections and discussions on realising these objectives can be found in the literature, with small clusters around informing educators about 3DP during their teacher training; informing active educators as part of professional development; and informing library professionals.

\section{A. Learning by Making}

Roffey et al. (2016) [29] explained that for education, the constructivist and constructionist activities are known as Makerspace as dealing with the world by higher activities. 
Constructivism is the gaining of knowledge or skills through professionality of learning and observation. Through experience and reflecting and think deeply on these skilful, individuals built their knowledge and comprehension of the world. According to constructionist paradigms, within collaborative environments, students comprehend best by producing sensible objects through authoritative, real-life learning possibilities on life that allow for guidance. This concurrent process incorporates peer feedback. In constructionist learning, is the essential fundamental as placed on the progress of positive technological in students. Also, is the encouragement of learning through designing and sharing.

Kroski (2013) [30] \& Mehalik (2008) [31] reported that 3D printing directly connects with two other emerging educational concepts: makerspaces and design-based thinking. Design-based education (DBL) of trial and error is an open-ended process, innovation, and iteration Makerspaces and DBL activities meant to encourage student-driven learning through exploration and the construction of artefacts. These activities assist students in developing their creative thinking, inquiry learning, and problem-solving skills.

\section{B. Using 3D Printing To Produce Artefacts That Aid Learning}

Tillinget al.(2014)[32] reported that using 3D printing to produce artefacts that aid learning as educational equipment "could be printed to encourage educators in almost every system". It was found that evidence of 3DP techniques is already being used to produce artefacts to aid education in a number of topics. Smith et al.(2017)[33], reported that 3DP objects are being used to support teaching in anatomy and chemistry as an active methodology.

\section{Assistive Technologies}

Assistive Technology (AT) could be websites, selecting, articles, blog posts, and videos based on understanding, and assessing assistive technology. AT is a set of devices intended to help people activities whenever it is difficult. Many assistive devices are built using the 
techniques of artificial intelligence (AI), including real-time speech-to-text transcription and visual recognition equipment.

Buehler et al. (2016) [34] indicated that 3DP is being used in particular education settings for those suffering visual, motor and cognitive impairments. There are two wide categories of application:

- When the artefacts designed by 3DP for those in need assistive technologies.

- When those with particular learning requires a real-world setting to student projects.

\section{Using 3D Printing To Support Outreach Activities}

In an outreach function, 3DPrint Company is considered as "primarily envisioned as producing CubeSat frames and a supplier of testing services in near-space conditions. Due to the lack of inexpensive parts services in the CubeSat industry, who are seeking to create a 3D printed involving a module and remotely controlled airship that could help a space satellite, test platform, and even launch into space platform for small rockets[35].

\section{E. 3D Printing Applications}

3D printing in 'Rapid Prototyping' was originated as a foundation of a system of industrial prototyping, to speed up the earliest performance of producing prototypes. Rapid prototyping allows for multiple reestablishments of product to arrive more quick and efficient at the solution of the most favourable condition. 3D print saves time, money and ensures confidence in production equipment.

\section{F. Beginner's Guide To 3D Printing}

This guide aims to supply the fundamental concepts of how to 3D print provided with the tools and required resources. The types of $3 \mathrm{D}$ printing, the software that powers it, how the hardware works, and other crucial information that help to get started. 


\section{TYPES OF 3D PRINTING:}

Three-dimensional printing (3DP) as an additive manufacturing technology (Singh, 2017) [36]:

1. Fused deposition modelling (FDM), (FFF)

2. Stereolithography (SLA),

3. Laser sintering (SLS).

4. Extrusion / FDM / FFF.

5. Selective Deposition Lamination (SDL)

6. Z-Printers.

\section{A. FDM - Fused Deposition Modelling}

Horn (2012) [37] \& Carneiroa et al., (2015)[38]\& Yu-an Jina et al.,(2015)[39]reported that Fused Deposition Modelling, is used for modelling, prototyping and production applications. FDM operates on an "additive" system by material in layers over layers. A coil and supplies material in the form of a plastic filament or metal wire is unwound to an extrusion nozzle where the flow on and off can be controlled while the nozzle is heated to melt the material. The nozzle can be moved in $(\mathrm{x}, \mathrm{y} . \mathrm{z})$ directions directly controlled by computer-aided manufacturing (CAM) software package as a digital controlled mechanism. The model or parts protrude by extruding small beads of thermoplastic material to form layers while the material hardens immediately after the extrusion. The 3D printing technology is involved with building up of very tiny layers of material, layer by layer, gaining the required 3D form.

FDM the technique using layers of materials to be fused together in a pattern to create an object. The material is usually melted just past its glass transition temperature, and then extruded in a pattern next to or on top of previous extrusions, creating an object layer by layer as shown in fig (8).

In layman's terms, a typical FDM 3D printer takes a plastic filament and squeezes it through a hot nozzle, melting it and then depositing it in layers on the print bed. 


\section{B. Extrusion / FDM / FFF}

The most popular name for the process is as Free Form Fabrication (FFF).The earliest RepRap machines and all subsequent. The process works by melting plastic filament that is deposited, via a heated extruder, a layer at a time, onto a build platform according to the 3D data supplied to the printer. Each layer hardens as it is deposited and bonds to the previous layer as shown in fig (9). The most common materials for entry-level FFF 3D printers are ABS and PLA.

\section{SLA - Stereo Lithography3d Models}

The machine was named the Stereolithographic Apparatus, as it utilized Stereolithographic as the process for printing 3D models. Since the development of this machine, rapid developments have occurred in the field of 3D printing which employs a vat of liquid curable photopolymer "resin" and an ultraviolet laser to build parts' layers one at a time. For each layer, the laser beam traces a cross-section of the part pattern on the surface of the liquid resin. Exposure to the ultraviolet laser light cures and solidifies the pattern traced on the resin and joins it to the layer below as shown in fig $(8$, 9).

Mandan et al. (2018)[40] reported that Laser Sintering technology can print different materials such as plastic, metals, ceramics, etc. These 3D printers are more developed to a high degree of complexity and more expensive.

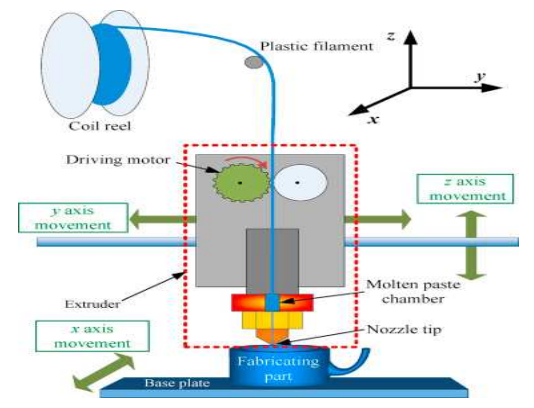

Fig (7) Illustration of the FDM technique [6].

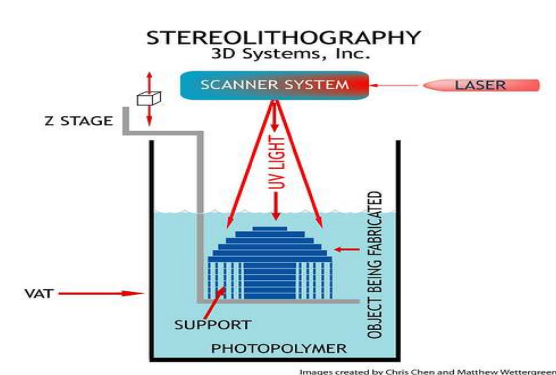

Fig (8) Stereo lithography3D models 


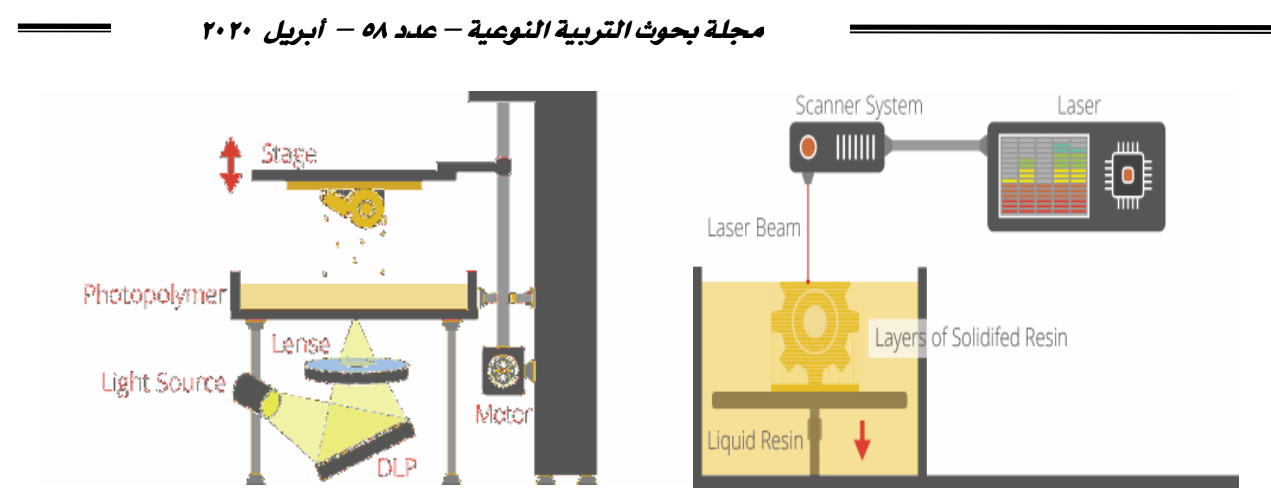

Fig (9). Illustration of the Stereolithography. Fig (10). Illustration of the DLP.

Stereolithography SL is a laser-based process that works with photopolymer resins that react with the laser and cure to form a precisely solid to produce very accurate parts. It is a complicated process but simple to operate. The photopolymer resin is kept in a vat with a movable platform inside. A laser beam then is directed on the X-Y axes through the resin surface. According to the supplied 3D data to the machine, the resin crucifies precisely while the laser hits the surface. The platform in the vat drops down by a fraction (in the $\mathrm{Z}$-axis) when the layer is completed. The consequent layer is tracked out by the laser. This process continues until the complete object is finished and the platform can be raised out of the vat for removal. DLP. Digital light processing (DLP) is an identical approach to stereolithography. DLP is a 3D printing approach that works with photopolymers materials. The differences between the two techniques only are the light source. DLP uses an arc lamp, a more unadventurous light source shown in fig (10).

\section{Laser Sintering / Laser Melting}
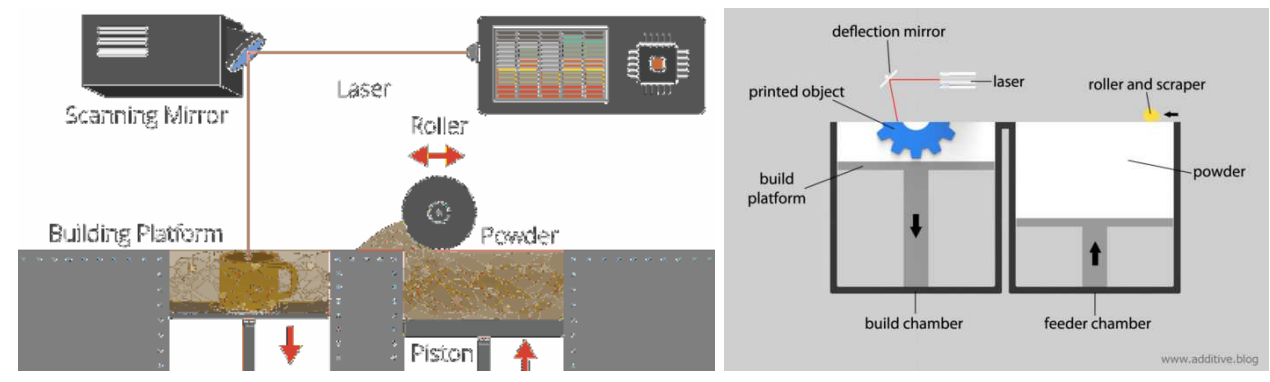

Fig (11) Laser Sintering / Laser Melting 
Laser sintering and laser melting are synonymous terms belonged to a laser-based 3D printing process, works with powdered materials. The laser is traced across of tightly compacted powdered material, according to the 3D data fed to the machine, in the X-Y axes. As the laser reacts with the powdered surface material, it sinters or fuses, the particles forming a solid shape. Whenever any layer completed the powder incrementally drops and the rollers smooth the powders over the surface. Therefore, complex shapes could be manufactured with this process. Laser sintering can fed plastic and metal materials, although metal sintering does require a much higherpowered laser and higher in-process temperatures. Parts produced with this process are much more durable, as shown in fig (11).

\section{E. Selective Deposition Lamination (SDL)}

SDL is a $3 \mathrm{D}$ printing process developed as a temptation to compare this process with the Laminated Object Manufacturing (LOM) process developed due to similarities in layering and shaping paper to form the final part. The SDL 3D printing process builds layer by layer working with a standard paper copier. Each new layer is fixed with the previous layer by proper adhesive, which is applied selectively by the 3D data supplied to the machine. The SDL uses a higher density of resin as deposited in the area of the central part, and a much lower adhesive density applies in the surrounding area to serve as the support, as removal support as shown in fig(12).
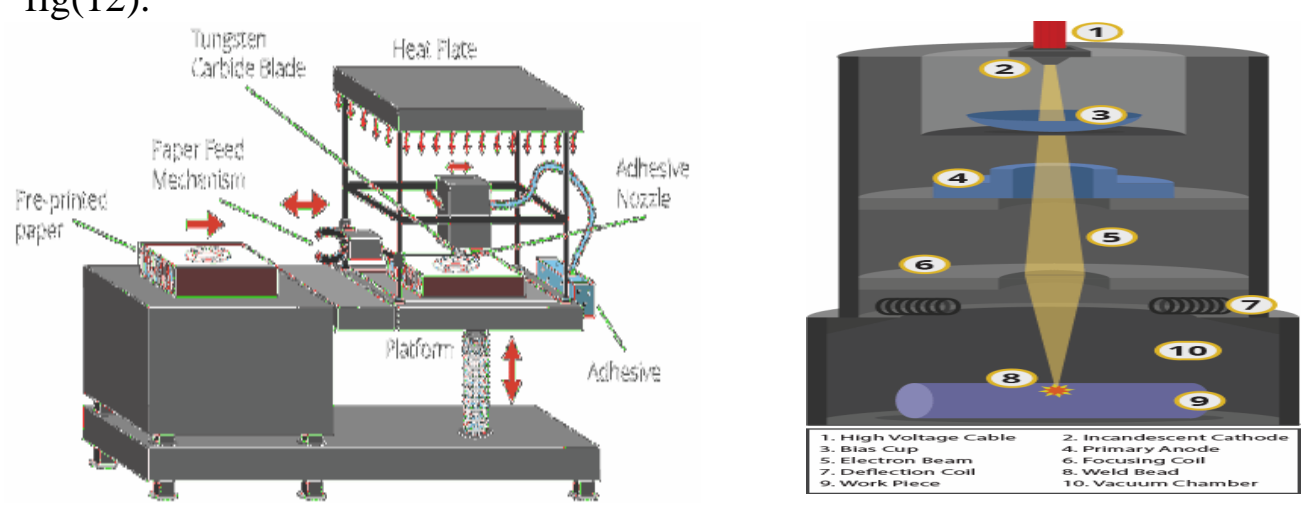

Fig (12) Selective Deposition Lamination Fig (13) the Electron Beam Melting. 
SDL is 3D printing processes can produce full-colour 3D printed parts, using a CYMK colour palette. SDL requires no post-processing; they are safe and eco-friendly. The process is not competing with other 3D printing operation, and the build size is limited to the size of the feedstock.

\section{F. EBM}

The Electron Beam Melting (EBM) 3D printing technique is very similar to the Direct Metal Laser Sintering (DMLS) process. The heat source is an electron beam, rather than a laser, which is carried out under vacuum conditions as shown in fig (13).EBM is capable of creating fullydense parts in a variety of metal alloys, even to medical-grade. The technique is particularly successful for a range of applications in the medical industry, particularly for implants, automotive manufacturing fulfilment and aerospace.

\section{G. Z-Printers,}

Z-Printers Is an additive manufacturing technique 3DP is using a high power laser (a carbon dioxide laser) to melt small particles of plastic or metal (metal laser sintering), ceramic, or glass powders into a 3D form. The laser melts powdered material selectively by scanning cross-sections generated from a 3-D digital technique. Over the bed, the powder is lowered by one layer thickness. After each cross-section is scanned, a new layer of material applied on top, and the operation is occurring again until the part is finished as shown in fig (14).

Hatch (2014) [41] \& Thompson et al. (2015) [42] reported that ZPrinters is the third major technology, are sophisticated and more expensive. It utilises a powdery substance that solidifies with a sprayed binding chemical. Thompson et al. "provided an overview of the major advancements, challenges and physical attributes related to Direct Laser Deposition (DLD) process. 


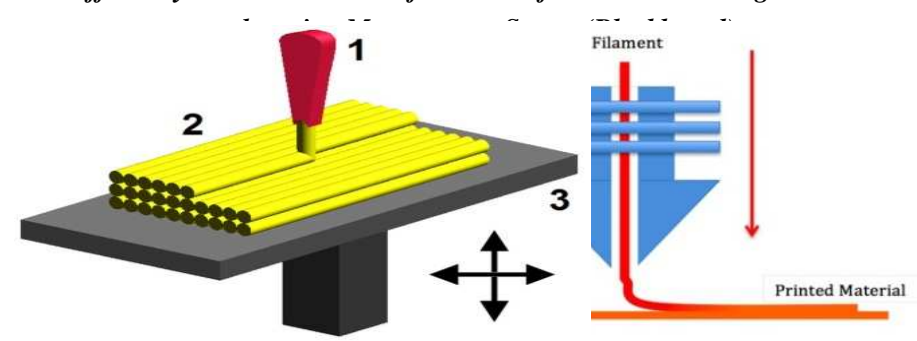

Fig (14) Z-Printers

A fused filament fabrication (FFF) printer works in the following way:

(1)A heated nozzle ejects molten plastic,

(2) depositing thin layers; one on top of another

(3) Print bed.

In order to draw a particular pattern, the nozzle or the print bed (or both) move while plastic materials is being extruded.

\section{3D PRINTING MATERIALS}

There is now a wide variety of different material types, which are supplied in different states (Metals powder, filament, pellets, granules, resin etc.). Specific materials are now generally developed for specific platforms performing dedicated applications with material properties that more precisely suit the application.

\section{A. Plastics}

Nylon, or Polyamide, is commonly used in powder form with the sintering process or in filament form with the FDM process. It is a strong, flexible and durable plastic material that has proved reliable for $3 \mathrm{D}$ printing. It can be white and coloured - pre- or post-printing. ABS (acrylonitrile butadiene styrene) is another common plastic used for $3 \mathrm{D}$ printing, and is widely used on the entry-level FDM 3D printers in filament form. It is a particularly strong plastic and comes in a wide range of colours. Figure $(15,16)$ is showing two images for the plastics 3D print. 


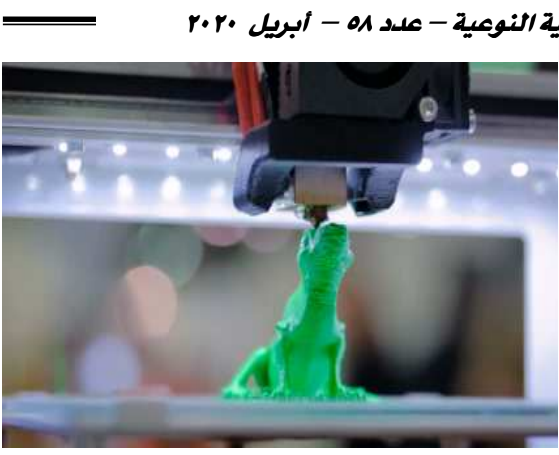

Fig (15)

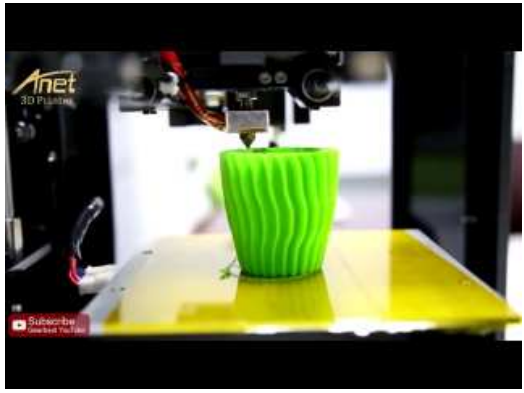

Fig (16)

\section{B. Metals}

Aluminium and cobalt are the two of the most common metals are derivatives used for 3D printing industrial-grade. Stainless Steel one of the strongest in powder forms for 3D printing. Stainless Steel employs for the sintering/melting/EBM processes. Silver can be plated with other materials to give the feature of gold or bronze effect. Gold and Silver can be 3D printed directly, with obvious applications across the jewellery sector.

Figures $(17,18)$ are showing 3D printing with metal forms.

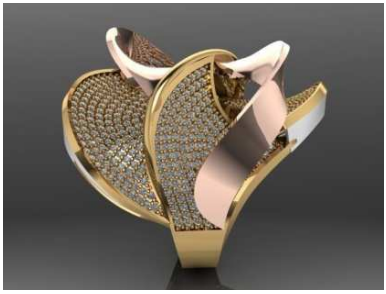

Gold and Silver

Fig (17)

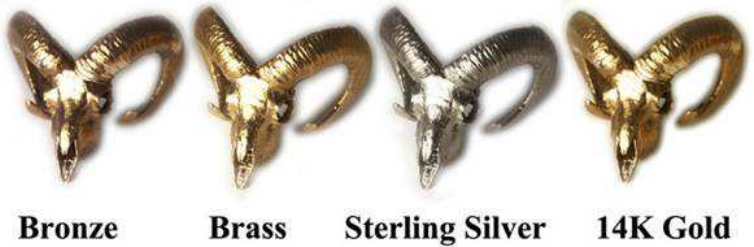

Bronze Brass Sterling Silver 14K Gold

\section{Ceramics}

A comparatively new group of materials are Ceramics that could be used for 3D printing and used primarily in post-printing need to undergo the processes of firing and glazing. Figures $(19,20,21)$ are showing 3D printing as metal forms. 


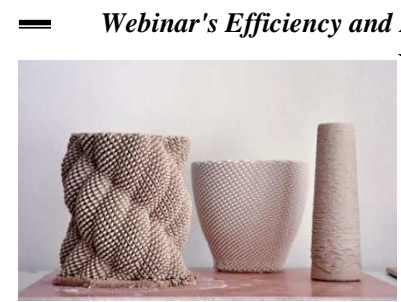

Fig (19)

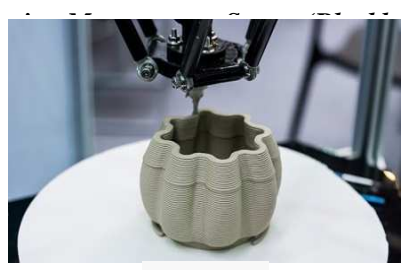

Fig (20)

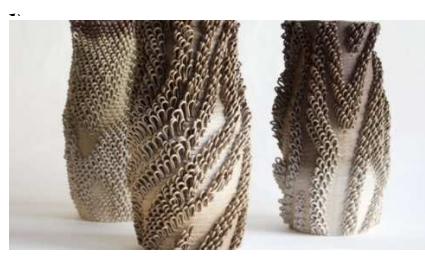

Fig (21)

\section{Paper}

3D printing materials employ Standard A4 copier paper by the SDL process. Still, the Standard A4 copier paper is very much on a readily available, low cost-effective material easily to supply and could be bought locally. 3D printed paper is safe, friendly environmental, recyclable and no need to post-processing. Figures $(22,23,24)$ are showing 3D printing as paper forms.

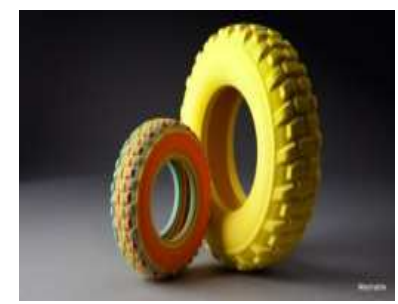

Fig (22)

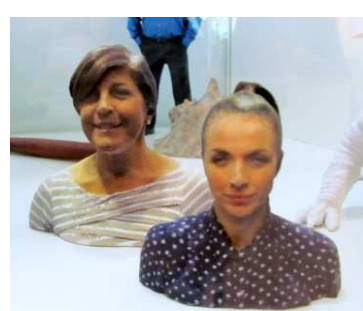

Fig (23)

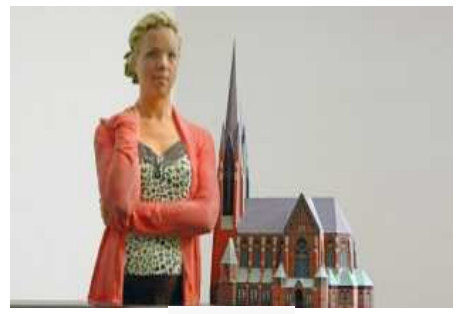

Fig (24)

3D printer makes product out of paper, ink, and glue

\section{E. Bio Materials}

Bagley et al. (2015) [43] \& Kröger et al. (2016) [44] have a research conducted into the potential of 3D printing biomaterials for a host of medical applications. Living tissue is being investigated to develop the applicability of 3DP of printing human organs for transplant, as well as external muscles for replacement body parts. Figures $(25,26,27)$ are showing 3D printing as human organs forms.

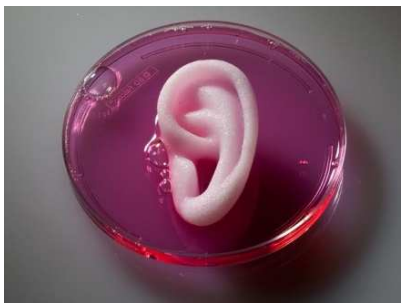

Fig (25)

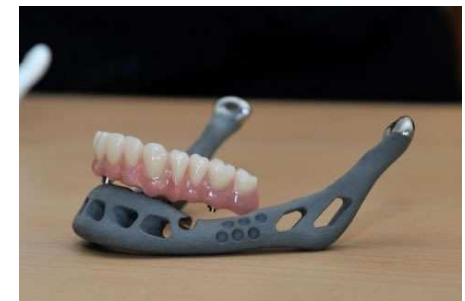

Fig (26)

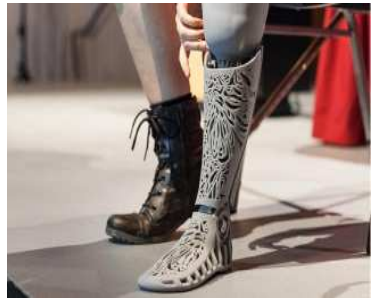

Fig (27) 


\section{ART / DESIGN / SCULPTURE}

Artists and Sculptors are most likely with 3D printing to explore form and function in ways previously impossible. With the age of the 3D printer, the artist has possibilities to innovate anything they require. This technology has been informed to almost every individual branch of the artwork and the final products are amazing. Figures $(28,29,30)$ are showing sculpture art with 3D printing technique.

3D Printing Art Design Sculpture.

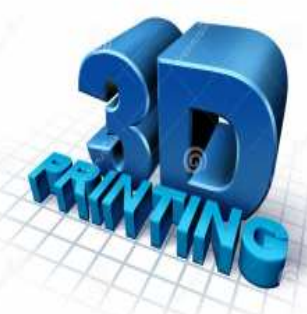

Fig (28)

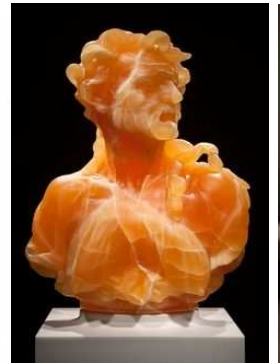

Fig (29)

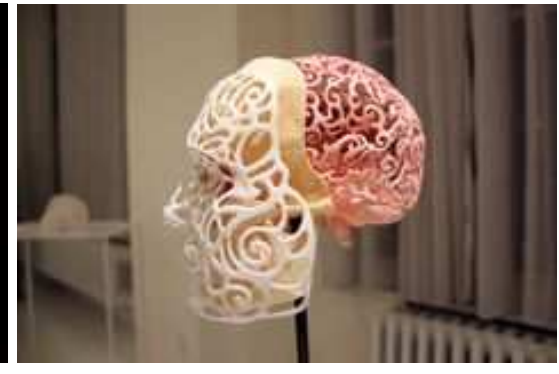

Fig (30)

\section{PRECAUTION OF DESIGNING A PART TO BE 3D PRINTED}

As far as the 3DP requires a CAD system to innovate the customer requirement, the $3 \mathrm{D}$ printing as manufactured by expensive hardware and materials consequently produce expensive parts; accordingly, it will be hard for mass production. This must be considered where the model requires removing up the protruding parts and the supports.

- The part should be a real volume and in solid surface.

- Creating very small, and delicate forms may not be printed properly,

- Parts with overhanging features will need supports to be printed properly.

- Calibrate the 3D printer before using is essential to make certain that the part fixed properly on the platform otherwise, the part will come loose and collapse the whole job.

- The orientation of the part should be carefully considered, especially on the 3 dimension of $\mathrm{X}, \mathrm{Y}, \mathrm{Z}$ axis. 


\section{Discussion and Conclusions}

Constructivists [45] emphasised that students required to be mentally and physically involved to gain and acquire knowledge and skill in new ideas and concepts. The arrival of digital innovation technologies such as desktop 3D printers now give the opportunity to students to demonstrate their ideas and connotation realised in materialistic form. This set of circumstances that make it possible to offers an opportunity to rethinking the curriculum and reconstruct essential interconnections among the different fields of the educational process. For example, fabrication Kits designed and manufacturing in engineering classes are being utilised to push forward learning through related experiments and practices in science classes.

Educators should consider 3DP as a crucial curriculum among other science technologies. Hence, the present research opinion is that sort of advanced education is a must in the educational process field. On the other hand, to give particular emphasis necessary for higher education targeting to raise the professionality of not only the technology for students but also the technology of the developers.

The present research discussed 3DP curriculums approaches for students, educators and lecturers in the higher education, trying to inject 3DP technology as a curriculum in art education, and to encourage the lecturers and educators to merge that technology and deliver those new techniques of the 3DP among the education process.

Lecturers obliged to integrate metacognitive access to educational curriculum, display inquiry-driven assignments that transfer the professional opportunities and coaching direction and opportunities over their education.

Furthermore, students can understand fully, stratify and describe the new knowledge more sufficiently, with the conclusion that "Students become having more obligation, motivation, engage and reach higher levels of education among the diversity of the learning styles of science.

The results of these studies would assist answer covering a large number and full scope of questions of how 3DP integrated into the 
educational process should and what institutional and national strategy is necessary to recognise this objective.

\section{REFERENCES}

[1] Ford, S. \& Minshall, T. Invited Review Article: Where and how 3D printing is used in teaching and education https://www.researchgate.net/publication/320617391;2017.

[2] Singh. \& Chhabra M. Three-Dimensional Printing in Reference Module in Materials Science and Materials Engineering; 2017.

[3] Available from.https://www.makersempire.com/st-stephens-school-takes-thefirst-step- Into-3d-printing-with-makers-empire-in-wa.

[4] Radniecki T. Supporting 3D modelling in the academic library, Libr. Hi Tech. 35 240-250. Doi: 10.1108/LHT-11-2016-0121; 2017.

[5] Goulas, A. \& Friel, R. "3D printing with moondust", Rapid Prototyping Journal, V. 22 No. 6, pp. 864-870. Available from. https://doi.org/10.1108/RPJ-02-2015-002;2016.

[6] Flowers A. Learning and Interpretation Available from.https://www.vam.ac.uk/blog/digital/taking-sculptures-for-a-walk-3dprinting-and-museum-outreach; 2016. [Cited 2020 Jan 19]

[7] 3D Printing: The Future of Art and Design. Available from .The Artifice .https://the-artifice.com/3d-printing-art-design/.

[8] Available from.https://formlabs.com/blog/resin-3d-printer-comparison-sla-vsdlp/

[9] Reuscher, J.A. (2014). Three-Dimensional (3-D) Scanning Within Academic Libraries: Exploring and Considering a New Public Service, Pennsylvania Libr. Res. Pract. 2. 64-70. doi:10.5195/PALRAP.2014.56.

[10] Domain Group (2013).Available from. Domain Group (2013). 3D Printing Workshop Notes. Malta special fund.europian social fund.

[11] Kalita, H. \& Kumar. (2020). Digital Technology Integration in Different Educational Fields: Design, Architecture, Tourism, and Business Engineering Chapter 2. Teaching and Learning: Pedagogy with Purpose .pp 20-27. DOI: 10.4018/978-1-7998- -5.ch008

[12] Software for 3D Printing, Advantages of 3D printing of the automotive industry. 3D Learning Hub. Available from.https://www.sculpteo.com/en/3d- 
- Webinar's Efficiency and Electronic Performance of Students with High and Low Motivation learning-hub/3d-printing-software/car-design-applications/.[cited 2020 April 19]

[13]. Irwin, J.L.; Pearce, J.M.; Anzalone, G. ; Oppliger. D.E. (2014). The RepRap 3-D Printer Revolution in STEM Education, in: ASEE Annu. Conf. Expo., ASEE, Indianapolis, USA: p. 24.1242.1- 24.1242.13.

[14] Ford, S. \& Minshall. Invited Review Article: Where and how 3D printing is used in teaching and education. [Cited 2020 Jan 19].Available from https://www.researchgate.net/publication/320617391. 2017.

[15] Go J. \& Hart, A.J. A framework for teaching the fundamentals of additive manufacturing and enabling rapid innovation, Addit. Manuf. 10. 76-87. doi:10.1016/j.addma.2016.03.001. 2016.

[16] Junk, S. \& Matt, R. (2015).New Approach to Introduction of 3D Digital Technologies in Design Education, Procedia CIRP. 36 .35-40. doi:10.1016/j.procir.2015.01.045. 2015.

[17] McGahern P.; Bosch, F.; Poli, D. Enhancing Learning Using 3D Printing: An Alternative to Traditional Student Project Methods, Am. Biol. Teach. 77 (2015) 376-377. doi:10.1525/abt.2015.77.5.9.2015.

[18] Janković, N.Z.; Slijepčević M.Z.; Čantrak, Đ.S. and Gađanski, I.I. Application of 3D Printing in M.Sc. Studies -Axial Turbo compressors, in: Int. Conf. Multidiscipline. Eng. Des. Optim. IEEE, Belgrade, Serbia, 2016: pp.96-99. doi:10.1109/MEDO.7746545. 2016.

[19] Fernandes S.C.F. \& Simoes, R. Collaborative use of different learning styles through 3D printing, in: 2nd Int. Conf. Port. Soc. Eng. Educ., IEEE, Vila Real, Portugal, 2016. doi:10.1109/CISPEE.2016.7777742. 2016.

[20] Loy, J. eLearning and eMaking: 3D Printing Blurring the Digital and the Physical, Educ. Sci. 4 108-121. Doi: 10.3390/educsci4010108. 2014.

[21] Liou, F.W.; Leu, M.C. Landers, R.G. Interactions of an Additive Manufacturing Program with Society, in: 23rd Annu. Int. Solid Free. Fabre. Symp. Laboratory for Freeform Fabrication and University of Texas at Austin, Austin, USA, pp. 45-61. 2012.

[22] Jaksic, N.I. New Inexpensive 3D Printers Open Doors to Novel Experiential Learning Practices in Engineering Education, in: ASEE Annu. Conf. Expo., 
ASEE, Indianapolis, USA, 2014: p. 24.932.1- 24.932.23. https://peer.asee.org/22865. 2014.

[23] Ahmad B.; AlAli, Michelle F. Griffin, Wenceslao M. Calonge, Peter E. Butler. Evaluating the Use of Cleft Lip and Palate 3D-Printed Models as a Teaching Aid. Journal of Surgical Education \& Association of Program Directors in Surgery. Elsevier Inc. 1931-7204/\$30.00 Available from.http://dx.doi.org/10.1016/j.jsurg.07.023. 2017.

[24] Losco, C.D., Grant, W.D., Armson, A., Meyer, A.J., Walker, B.F. Effective methods of teaching and learning in anatomy as a basic science: a BEME systematic

Review: BEME guide no. 44. Med. Teach. 39 (3), 234-243, Available from .http://dx.doi.org/10.1080/0142159X.2016.1271944, Epub. 2017.

[25] Wilson, A.B., Miller, C.H., Klein, B.A., Taylor, M.A., Goodwin, M., Boyle, E.K., Brown, K., Hoppe, C., Lazarus, M. A meta-analysis of anatomy laboratory pedagogies. , [sited 2020 Jun 13].Clin. Anat. 31 (1), 122-133, Available from http://dx.doi.org/10.1002/ca.22934.2017.

[26] Vaccarezza, M. \& Papa, V., (2014). 3D printing: a valuable resource in human anatomy education. Anat. Sci. Int. 90 (1), 64-65, Available from .http://dx.doi.org/10.1007/s12565-014- 0257-7, Epub. Oct 7. 2018.

[27] Bull, G.; Chiu, J.; Berry, R.; Lipson, H.; Xie, C. Advancing Children's Engineering through Desktop Manufacturing, in: J.M. Spector, M.D. Merrill, J. Elen, M.J. Bishop (Eds.), Handb. Res. Educ. Commune. Technol., 4th ed., Springer Science Business Media, New York, 2014: pp. 675-688. Doi: 101007/978-1- 4614-3185-5. 2014.

[28] Maloy, R.; Trust, T.; Kommers, S.; Malinowski, I. and LaRoche, 3D Modeling and Printing in History/Social Studies Classrooms: A. Initial Lessons and Insights, Contemp. Issues Technol. Teach. Educ. 17229-249. 2010 [cited 2019 Des 19]. 2017. [cited 2019 Sept. 22] Available from https://citejournal.s3.amazonaws.com/wp-content/uploads/v17i2socialstudies1. pdf.

[29] Roffey, T.; Sverko, C.; Therein, J. The making of a Makerspace: Pedagogical and Physical Transformations of Teaching and Learning. University of British Columbia 4/3/2016.2016. 


\section{= Webinar's Efficiency and Electronic Performance of Students with High and Low Motivation}

[30]Kroski, E. A librarian's guide to makerspaces: 16 resources. Available from the Open Educational Database: 2013. [Available from. Available from http://oedb.org/ilibrarian/a-librarians-guide-tomakerspaces/.

[31] Doppelt, Y.; Mehalik, M. M.; Schunn, C. D.; Silk, E., \& Krysinski, D. Engagement and achievements: A case study of design-based learning in a science context. Journal of Technology Education, 19(2), 22-39. 2008.

[32] Tillinghast, R.C. ; Wright, M.T. ; Arnold, R.D. ; Zunino, J.L. ; Pannullo, T.L. ; Dabiri, S. E.A. Petersen, M.C. Gonzalez, Integrating Three Dimensional Visualization and Additive Manufacturing into K-12 Classrooms, in: 2014 IEEE Integr. STEM Educ. Conf., IEEE, Princeton, USA, doi:10.1109/ISECon.2014.6891051. 2014.

[33] Smith, M.L. \& Jones, J.F.X. Dual-Extrusion 3D Printing of Anatomical Models for Education Construction of Airway Models, Anat. Sci. Educ Forthcoming. doi:10.1002/ase.1730. 2017.

[34] Buehler, E.; Comrie, N.; Hofmann, M. ;McDonald, S. and A. Hurst, Investigating the Implications of 3D Printing 31 in Special Education, ACM Trans. Access. Compute. 8 (2016) 1-28. Doi: 10.1145/2870640. 2016.

[35] Stratodyne. 2020.[Sited 2020 apr.20]. Available from .https://3dprint.com/264585/stratodyne-new-space-company-wants-to3.Print- Stratospheric-satellites-and-cubesats/.

[36] Singh, R. \& Chhabra, M. In Reference Module in Materials Science and Materials Engineering. 2017.

[37] Horn, TJ. \& Harrysson, OLA. Overview of current additive manufacturing technologies and selected applications. Science Progress 95(3):255-282. Doi: 10.3184/003685012x13420984463047’'2012.

[38] Carneiroa, O.S.; Silvab A.F and Gomesa R. Fused deposition modelling with polypropy lene.v Materials \& Design. 2015, Pages 768-776. 2015.

[39]Yu-an Jina, c. Hui Li b.; Yong Hea, c. and Jian-zhong Fua. Quantitative analysis of surface profile in fused deposition modelling. Additive Manufacturing. Volume 8, Pages 142-148. 2015.

[40] Manda, V.; Kampurath V. and Chaitanya M. 3D Printing and its Effect on Outsourcing: A Study of the Indian Aircraft Industry. Journal of Aerospace Technology and Management 10. 2018. 


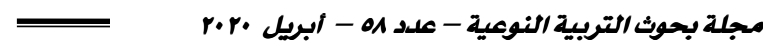

[41] Hatch, M. The Maker Movement Manifesto: Rules for innovation in the new world of crafters, hackers, and tinkerers. New York: McGraw Hill Education. 2014.

[42]Thompson SM, Bian L, Shamsaei N, Yadollahi A. An overview of Direct Laser Deposition for additive manufacturing; Part I: Transport phenomena, modelling and diagnostics. Additive Manufacturing 36-62. Doi: 10.1016/j.addma.2015.07.001.2015.

[43] Bagley, J.R. \& Galpin, A.J. Three-Dimensional Printing of Human Skeletal Muscle Cells: An Interdisciplinary Approach for Studying Biological Systems, Biochem. Mol. Biol. Educ. 403-407.doi:10.1002/bmb.20891.2015.

[44] Kröger, E. ; Dekiff, M. And Dirksen, A. 3D printed simulation models based on real patient situations for hands-on practice, Eur. J. Dent. Educ. (n.d.) 1-7. doi:10.1111/eje.12229. 2016.

[45] Bull G.; Haj - Hariri, H.; Atkins, R. and Moran, P. An Educational Framework for Digital Manufacturing in Schools. 3D Printing Vol. 2 No. 2. DOI: 10.1089/3dp.2015.0009.2015. 


\section{الأبعاد الفنية لتقنيات الطباعة ثلاثية الأبعاد في هجال الفنون ونظام التعليم}

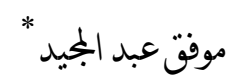

\section{الملص العربي}

تتحكم تقنيات الطباعة ثلاثية الأبعاد يِّ عمل العديد من الآلات أو العمليات أو الأنظمة

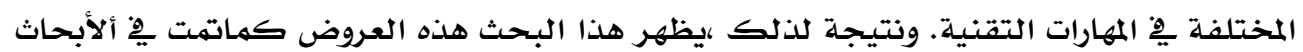

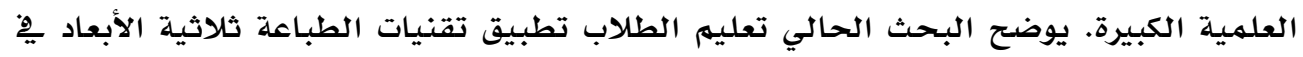

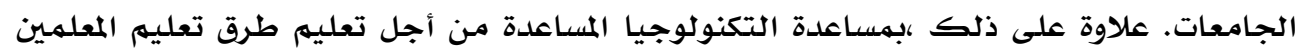

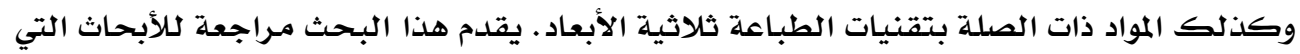

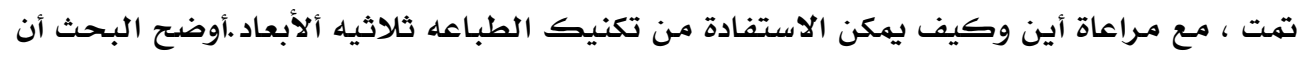

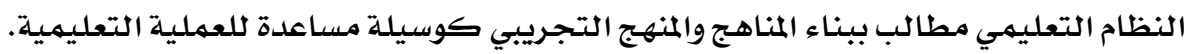

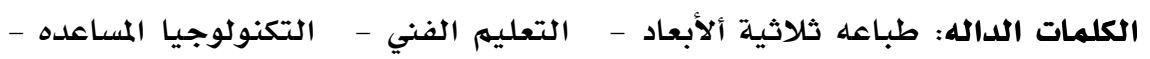
ألإسلوب التجريبي 